\title{
Seclusion and restraints: a neglected area of research in child and adolescent psychiatry?
}

\author{
Benno Graf Schimmelmann
}

Published online: 30 March 2011

(C) Springer-Verlag 2011

The use of seclusion and restraints to manage aggression in children and adolescents raises ethical concerns and poses a conflict between patient's needs and legal rights [1]. The child and adolescent psychiatrist has to cope with the child's parental, societal and his own aversive feelings towards these techniques. Probably, almost every child and adolescent psychiatrist will remember his first encounter during training with an aggressive patient, to whom he needed to apply seclusion or restraints. Recently, the Dutch media reported about the physical restraint of a mentally disabled patient and thereby induced a public outcry; whereas, the government defended restraint if necessary and professionally applied (http://news.ninemsn.com.au/world/8200460/ dutch-government-defends-restraint-of-disabled). In thinking of these moments, the need for evidence-based standard procedures and guidelines backed by experts and the respective governments is obvious and urgent.

Already in 2002, Sourander and colleagues [1], who published a study in this journal on the prevalence and predictors of holding, seclusion and restraint in child and adolescent psychiatric in-patients in Finland, emphasised the need for comparing different practices and legal issues on seclusion and restraints in different EU countries and recommended the formulation of common guidelines. In this issue of European Child and Adolescent Psychiatry, almost a decade later, De Hert and colleagues [2] systematically reviewed the literature on the prevalence, indications, predictors and outcomes of seclusion and restraints in children and adolescent between 2000 and

B. G. Schimmelmann $(\bowtie)$

University Hospital of Child and Adolescent Psychiatry,

Bolligenstr. 110, 3000 Bern 60, Switzerland

e-mail: bschimme@aol.com
2010. This timely review provides some good and some bad news: one of the bad news is that the authors had found only seven studies, which properly assessed the outcome of a seclusion/restraints procedure by means of a pre-intervention/post-intervention design. One of the good news is that standard procedures can indeed decrease the prevalence and duration of seclusion and restraint. While probably most of today's child and adolescent psychiatric services have standard procedures on the prevention and use of seclusion and restraints, their details and effectiveness may vary widely. Therefore, De Hert and colleagues righteously call for more research and, again, for guidelines in the EU.

The original study presented by Müller et al. [3] in this issue illustrates that mentally ill mothers tend to view their children's behaviour differently than healthy mothers. This is particularly interesting, since child and adolescent psychiatry commonly uses multi-informant assessments including mother's reports of a child's behaviour to base diagnostic and therapeutic decisions on. Their findings should guide researchers and, subsequently, clinicians to refine standard diagnostic procedures by measuring and weighing the impact of parental psychopathology. This issue also contains a review of 17 studies and accompanying case series on the effectiveness of melatonin for the treatment of sleeping problems in autism by Doyen et al. [4], an understudied and clinically relevant area of research. The authors propose melatonin as a promising alternative to other psychopharmacological treatment options for sleeping disorders such as antipsychotics.

In Conclusion, this issue of European Child and Adolescent Psychiatry once again provides up-to-date reviews and original research. Despite the ongoing advances in evidence-based medicine in our field [5, 6], significant gaps of knowledge and guidelines are being brought to our 
attention and ought to spur on our research and clinical thinking.

\section{References}

1. Sourander A, Ellilä H, Välimäki M, Piha J (2002) Use of holding, restraints, seclusion and time-out in child and adolescent psychiatric in-patient treatment. Eur Child Adolesc Psychiatry 11(4): $162-167$

2. De Hert M, Dirix N, Demunter H, Correll CU (2011) Prevalence and correlates of seclusion and restraint use in children and adolescents: a systematic review. Eur Child Adolesc Psychiatry. doi:10.1007/s00787-011-0160-x
3. Müller JM, Achtergarde S, Furniss T (2011) The influence of maternal psychopathology on ratings of child psychiatric symptoms: an SEM analysis on cross-informant agreement. Eur Child Adolesc Psychiatry. doi:10.1007/s00787-011-0168-2

4. Doyen C, Mighiu D, Kaye K, Colineaux C, Beaumanoir C, Mouraeff Y, Rieu C, Paubel P, Contejean Y (2011) Melatonin in children with autistic spectrum disorders: recent and practical data. Eur Child Adolesc Psychiatry doi:10.1007/s00787-011-0162-8

5. Rutter M (2010) Child and adolescent psychiatry: past scientific achievements and challenges for the future. Eur Child Adolesc Psychiatry 19(9):689-704

6. Reef J, Diamantopoulo S, van Meurs I, Verhulst F, van der Ende J (2010) Predicting adult emotional and behavioural problems from externalizing problem trajectories in a 24-year longitudinal study. Eur Child Adolesc Psychiatry 19(7):577-586 